\title{
Using social marketing concepts to promote the integration of systematic conservation plans in land-use planning in South Africa
}

\author{
Angelika Wilhelm-Rechmann, Richard M. Cowling and Mark Difford
}

\begin{abstract}
Local land-use planning procedures are increasingly recognized as potentially crucial to ensure off-reserve biodiversity protection. Mainstreaming systematic conservation planning maps in these decision-making procedures has been proposed as a mechanism to achieve this. However, research is lacking on how to convince officials and politicians to change their behaviour and include the maps in their decision-making. Social marketing is a tool commonly used to effect behaviour change in many sectors but its application in conservation is limited. In the formative research phase of a social marketing study we interviewed locally elected politicians in four coastal municipalities in South Africa. We found that conservation and environmental issues play virtually no role in their work; however, they do attribute value to the natural environment. Land-use planning procedures are considered important but dysfunctional and the role of conservation is perceived negatively in their municipalities. Their information-seeking behaviour is clearly localized. We present a marketing analysis of these results and argue for improving the attractiveness of the product: the maps should be more option- than veto-based and should identify locally relevant ecosystem services. Locally significant information should be provided at a time and location convenient for politicians. We conclude that engagement with councillors should be proactive, refer to land-use planning and services from 'nature' rather than 'biodiversity' and use terminology and information that is locally oriented and meaningful from the politician's perspective. The analysis highlights the usefulness of the marketing approach for conservation.
\end{abstract}

Keywords Audience research, communication, formative research, implementation, land-use planning, mainstreaming, social marketing, systematic conservation planning

This paper contains supplementary material that can be found online at http://journals.cambridge.org

Angelika Wilhelm-RechmanN ${ }^{*}$ (Corresponding author), Richard M. CoWling and Mark Difford Department of Botany, Nelson Mandela Metropolitan University, Port Elizabeth, South Africa. E-mail a.rechmann@ mweb.co.za

${ }^{*}$ Current address: Schrockstr. 23a, 14165 Berlin, Germany

Received 11 November 2011. Revision requested 11 January 2012.

Accepted 17 February 2012. First published online 7 August 2013.

\section{Introduction}

T ocal land-use planning procedures are increasingly 1 recognized as a strategic focus for the conservation sector to guide land transformation, a major driver of biodiversity loss (Theobald et al., 2000; Opdam et al., 2002). Using conservation assessment software, scientists have developed spatially explicit maps for many parts of the world that indicate which areas are most valuable for biodiversity protection. One aim of developing these maps is to steer development away from areas with high biodiversity value (Pressey, 1999; Pierce et al., 2005; Reyers et al., 2007). Most of these conservation assessments are conceptualized in the systematic (target-driven) mould (Margules \& Pressey, 2000) and framed in terms of biodiversity concepts such as irreplaceability, complementarity, threat, connectivity, viability, and ecological and evolutionary processes. The resultant geographical information system (GIS)-based maps are likely to be incomprehensible to non-specialist users. Pierce et al. (2005) provide the only documented attempt, to our knowledge, to mainstream conservation planning products into land-use planning processes at the local government level. However, effective mainstreaming requires an understanding of how biodiversity conservation is perceived by local government bodies and officials, and of the role that conservation and the conservation planning products have or could have in land-use decision-making (Miller et al., 2008; Stokes et al., 2010).

One approach with potential for influencing human behavioural choices regarding environmental sustainability is social marketing (Andreasen \& Tyson, 1994; Whiteman, 1999): '... the application of commercial marketing technologies to the analysis, planning, execution and evaluation of programs designed to influence the voluntary behaviour of target audiences in order to improve their personal welfare as well as that of their society' (Andreasen, 1995, p. 7). With the exception of the example given in Landers et al. (2006), conservation science has rarely adopted social marketing as a means to engender behaviour change among target audiences. RARE, a US-based conservation NGO well known for using advertising and marketing strategies to further conservation, has recently adopted a formalized behavioural approach, as in the above definition of social marketing, but has not so far published any of the results.

Here, we present results from the formative research phase of a social-marketing project to identify strategies for 
mainstreaming maps into local government land-use planning processes. This research phase investigates, in an audience-centred approach, how the target group relates to the planned behaviour change (Wilhelm-Rechmann \& Cowling, 2008). The core question we address is: how can conservationists effectively contribute to changing the behaviour of elected municipal councillors towards regular inclusion of these maps in the land-use planning decisionmaking they oversee?

Marketing philosophy is grounded in the concept of exchange (Zafirovski, 2003). For a transaction to take place the product must provide benefits perceived to be desirable for the buyer (the councillor), and the investment (or price) must be low enough to enable, or at least not prevent, the transaction. The actual product we are marketing is the new behaviour (Andreasen, 2006), which, in this case, is ensuring that the maps guide land-use planning decisions. The price consists of any investment the councillors have to make to adopt the maps; for example, the energy and time invested to understand or use them or to deal with potential conflicts emanating from their use. If this price is too high, it acts as a barrier to the transaction. For a behaviour change to happen (i.e. for the councillors to adopt the maps) the benefits must outweigh the investment. Using this exchange paradigm we rephrase our core question thus: what benefits that are inherently connected with using the maps can we provide or highlight, and what barriers need to be lowered or overcome, so that the councillors will adopt the behavioural product we promote, which is 'use the maps'?

To investigate this core question we address a number of sub-questions that explore the contextual parameters determining if the maps are used. The questions are based on and complement our prior research (Wilhelm-Rechmann \& Cowling, 2011; Wilhelm-Rechmann \& Cowling, 2013). Firstly, what role does environmental or biodiversity protection play in councillors' daily lives and in relation to other political issues (in marketing terms, what role does or could the product play and what other issues are we competing with)? Secondly, how do councillors relate to their natural environment in their work as well as in their personal lives (is the natural environment itself perceived as a benefit)? Thirdly, how do councillors perceive land-use planning (what role does it play in the municipality)? Fourthly, how do councillors perceive conservation (does conservation have a connotation of benefit)? Fifthly, where will councillors routinely seek information or help (what communication channels can we use to convey the strategic benefits of using the maps in a way that is convenient and effective for them)? Lastly, how best do we communicate the strategic benefits of using the maps (what language, terminology, narrative and concepts could we use to promote behaviour change in a way that is captivating and compelling for the target audience)?
A commonly used marketing approach is the ' $4 \mathrm{Ps}$ ' (Kotler \& Keller, 2006), namely product, price, place and promotion. We oriented our investigations around these themes and suggest modifications to the conservation assessments (product); we highlight barriers to using the assessments (price); we recommend the most effective ways of reaching the audience (place); and we reiterate the need for appropriate communication (promotion). Note that each of the ' 4 Ps' can act as a benefit for or as a barrier to the transaction of exchange.

\section{Context}

The study area comprises four coastal municipalities in South Africa's Eastern Cape Province, the country's second poorest province. Culturally, $87.5 \%$ of the population are Black Africans (mainly isiXhosa speaking), $7.4 \%$ are Coloured, $0.3 \%$ are Indian/Asian and $4.7 \%$ are White Africans of European descent (StatsSA, 2009). All of the municipalities are characterized by huge disparities in wealth and land ownership, and high levels of poverty and unemployment. The majority of Black Africans live in impoverished conditions and most of the wealth is owned by a minority of White Africans.

Since the first democratic elections in 1994 the African National Congress (ANC) has governed in nearly all Eastern Cape municipalities by a considerable margin. The Democratic Alliance (DA) is the official opposition party for which most White Africans vote. Of the 60 councillors in the four municipalities, 42 were ANC, $14 \mathrm{DA}$ and four from other political organizations. All four municipalities are situated along the relatively unspoiled coastline, which is under pressure from urbanization driven by migration of wealthy White Africans seeking improved lifestyles and impoverished Black Africans seeking employment (Palmer et al., 2010).

The municipalities are part of the planning domain for the Subtropical Thicket Ecosystem Planning (STEP) project, a conservation-planning project aimed at identifying priorities and implementing actions for safeguarding subtropical thicket ecosystems (Pierce et al., 2005; Knight et al., 2010). STEP conservation planning products consist of maps (Fig. 1) that indicate by colour code how valuable a parcel of land is with regards to conserving biodiversity, and a handbook that provides information on the project, the value of biodiversity, the legal background pertaining to environment and land-use planning, and more specialized biological information. The aim of these planning materials and related workshops is to build the capacity of local government officials and to steer development away from conservation priority areas.

South African law endows the municipal sphere with the primary decision-making powers on land use and 
(a)

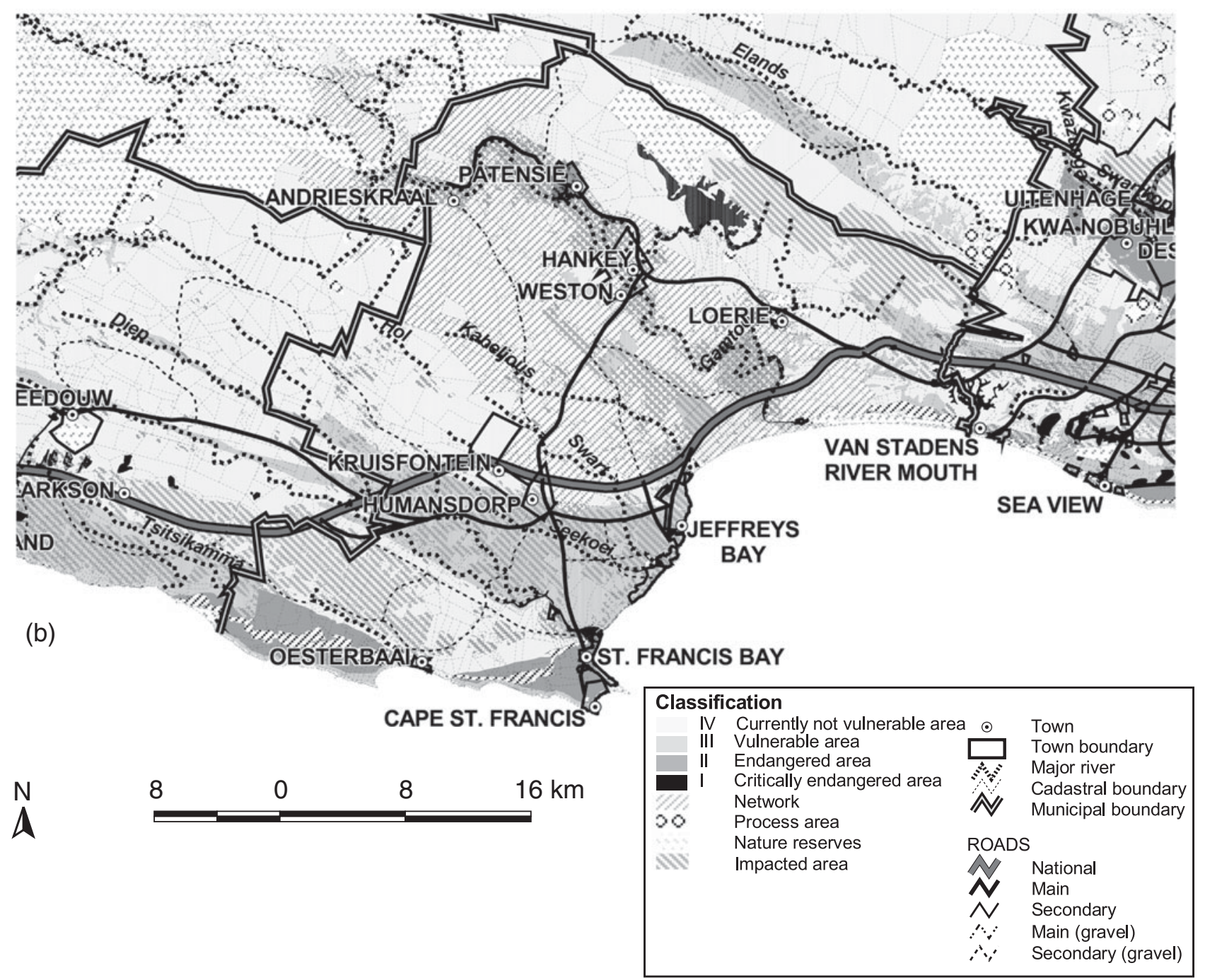

FIG. 1 Example of the conservation planning maps used in this project. Conservation priority maps of (a) the entire STEP planning region and (b) the Kouga Municipality (as published in Pierce et al., 2005). 
development planning (van Wyk, 1999). Locally elected councillors make the final decisions. There are, however, various obligations for consultation and compliance with provincial and national legislation. Two components of land-use planning and development need to be differentiated: the forward planning process, and the statutory landuse planning (LUP) process per se.

Legislation (the Municipal Systems Act) enacted in 2000 obliges municipalities or local councils to conduct Integrated Development Plans (IDPs), which reflect future development needs. Integrated Development Plans are developed in a bottom-up process reflecting the needs and aspirations of the local population in a way that is circumscribed by provincial and national requirements. A Spatial Development Framework (SDF) forms part of the IDP and is usually compiled by land-use planning consultants. The SDF is a spatially explicit plan that provides a technically informed vision of future land development, including, for example, land-use rights, zoning and development corridors. Spatial Development Frameworks are key informants in the LUP processes but they are not legally prescriptive as such.

South Africa has a long history of statutory land-use planning (Beinart, 2003) and, accordingly, a complex legal system is in place (van Wyk, 1999). This complexity is underpinned by the historical abuse of various planning tools to enforce racist practices devised by colonial and apartheid governments (Cousins et al., 2007), although much progress in introducing enlightened legislation has been made since the 1994 democratic elections. The key legislation currently in force in the project area is the Land Use Planning Ordinance, which dates from 1985. This ordinance and connected processes and legislation regulate in detail what use rights pertain to a land parcel, what processes need to be followed, and what conditions have to be respected by the municipality to change these use-rights.

\section{Methods}

One of us (AW-R) conducted 31 interviews with municipal administrators and experts in the land-use planning sector in the Eastern Cape to inform the development of the interview guide for councillors. AW-R then interviewed 38 (30 ANC, $8 \mathrm{DA}$ ) of the 60 councillors in the four municipalities. Because of the small number of possible interviewees we attempted to contact all of them. Of the 60 councillors, only two refused openly to give an interview and 20 were not reachable. The interview guide (Supplementary material) consisted of seven background questions and 10 open-ended questions. The interview opened with a brief description of the interviewer's background, the mainstreaming project, and a brief examination of the STEP maps. Interviewees were ensured confidentiality. To avoid possible influences of social desirability (the tendency to produce answers that are expected or desired by the interviewer, which may lead to falsified replies; Steenkamp et al., 2010) we avoided, where feasible, addressing the issues of biodiversity and the natural environment directly.

At the end of the interview we asked councillors to rank the following seven terms according to their importance in their work: biodiversity protection, environmental protection, social development, economic development, education and training, security, and service delivery. We chose these terms to cover the explicit issue at hand (biodiversity), all three aspects of the sustainability definition (economic, social and environmental), and the most prevalent political issues in South Africa (provision of basic services, education and crime). The approach ensured that our target topics of biodiversity and environment were forced into consideration, as the questionnaire was intentionally non-prescriptive in this respect.

All interviews were recorded and transcribed with permission, took 20-90 minutes and were conducted during September-December 2008. We analysed the transcripts to obtain the following background information: interviewee's cultural background (Xhosa, Coloured, Afrikaans, English), how long they had been a member of their political party (ANC or DA) and if they had been politically active prior to the 1994 democratic elections. We combined the last twomentioned questions in a qualitative assessment of the interviewee's political history.

We explored what training councillors had received for their current position, if such training had provided any biodiversity or environmentally related information, and who had conducted such training. We rated how experienced councillors considered themselves with regards to the use of a personal computer and if they could relate somehow to the term 'GIS'.

In the answers to our first open-ended interview question ('what are the priorities of your work?') we first rated if a reference had been made to any issue related to the natural environment. We then grouped the answers into the following three categories that emerged from the replies: service delivery, good governance, and other. For assessing all three aspects of the land-use planning processes (IDP, SDF and LUP), we used the same approach; i.e. we rated if interviewees were familiar with the process, if they considered the process to be valuable, and if they considered it to be functional. We explored the perceptions of councillors about the role of conservation in the municipality by categorizing responses into predominantly positive, positive and negative, predominantly negative, or neutral. With regards to the questions on what councillors and tourists value most in the municipality, we noted whether the natural environment featured. We explored councillors' 
information-seeking behaviour by categorizing responses according to where they would turn to as a first and as a second resort when needing assistance.

We assigned a score ( 7 , most important, to 1 , least important) to the rankings provided by the councillors of the seven issues presented to them. Terms rated as equally important were attributed equal rank. The ranked terms were converted to a set of paired comparisons and analysed as an intercept-only Bradley-Terry model (Bradley \& Terry, 1952). This calculates a worth parameter (or merit) for each term based on how well it performed in a set of head-tohead contests with the other terms. The analysis was carried out using Psychotree (Strobl et al., 2009). A network analysis of the ranked terms was implemented using a version of the PC algorithm (Spirtes et al., 2000) implemented in PCALG (Maathuis et al., 2010). Psychotree and PCALG are contributed packages for $R$ (R Development Core Team, 2010).

\section{Results}

\section{Background questions}

Approximately $60 \%$ of the interviewees considered themselves of Xhosa origin, 19\% Coloured, $16 \%$ White Afrikaans speakers and 5\% White English speakers. The proportion of White African and Coloured cultural groups is higher than the average for the general populace of Eastern Cape Province. Circa $75 \%$ of the interviewees were ANC members, which is equivalent to the provincial distribution of seats and representative of the four municipalities.

Seventy-three percent of councillors were involved in politics prior to the 1994 democratic elections, 10\% became involved since, and $17 \%$ were newcomers to formal politics ( $<5$ years). Significantly, $82 \%$ of the ANC councillors were involved in politics before 1994 (i.e. they were connected to the struggle against White supremacy), whereas $55 \%$ of the DA councillors were newcomers (i.e. they were involved in politics for $<5$ years). All interviewees indicated having received some training for their position: $68 \%$ referred to the South African Local Government Association as training provider and $51 \%$ to their political party. Most (86\%) councillors asserted that no biological or natural environmental issues featured in their training. Eighty-six percent of councillors declared having at least limited experience with personal computers but only $22 \%$ made regular use of the Internet. Similarly, only $22 \%$ had some notion of GIS.

\section{Topic questions}

The role of the natural environment in councillors' work None of the councillors identified natural environmental issues as a priority in their work. Service delivery was

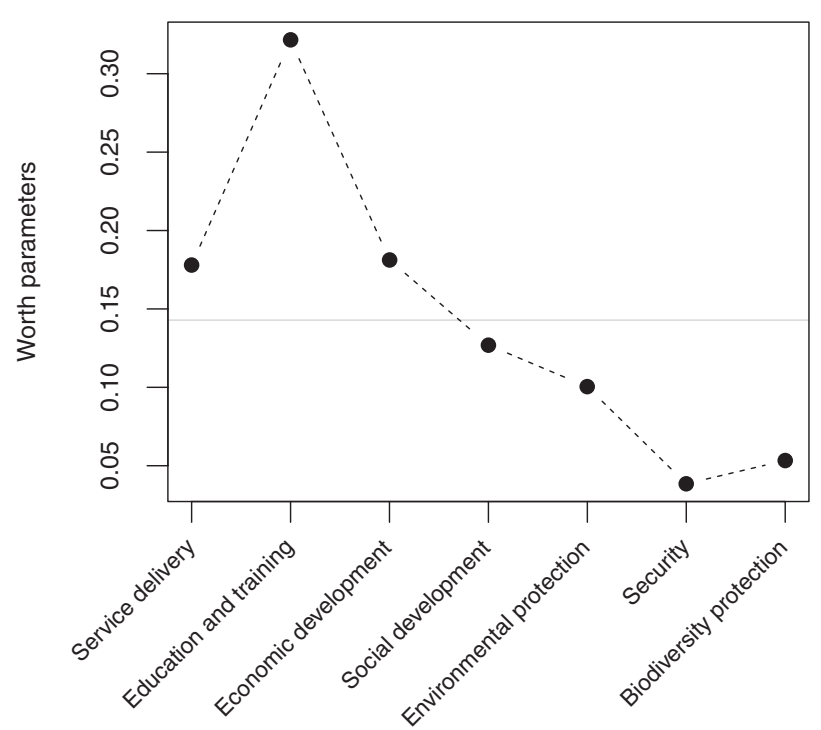

FIG. 2 Bradley-Terry paired comparison model of councillors' priorities. The horizontal line at 0.143 shows the mean worth of all priorities.

significantly over-represented as a priority, identified by $62 \%$ of councillors, followed by good governance (24\%) and other issues (14\%). Only four of 37 councillors mentioned any nature-related issues in the open-ended questions. Analysis of the scores of the seven ranked terms using a paired comparison approach clearly demonstrated that biodiversity and the environment occupied the bottom places in the hierarchy of importance (Fig. 2). The fitted model is highly significant $(\mathrm{P}<0.0001)$, based on a Wald $\chi^{2}$ test. Network analysis of the same data supplemented this result by showing where interventions could best be made to improve the priority placed on protecting biodiversity and the environment (Fig. 3). This analysis indicates that raising the priority placed on protecting the environment has a strongly positive effect on protecting biodiversity. All other priorities have a negative effect. None of the other priorities affect the priority placed on protecting the environment. The extracted network fits the observed data well, judged by Shipley's (2000) C test $(\mathrm{C}=22.97, \mathrm{df}=28, \mathrm{P}=0.7346)$ and the Bollen \& Stine (1992) bootstrap $\left(\chi^{2}=19.60, \mathrm{df}=14\right.$, $\mathrm{P}=0.1433$, using 5,000 bootstraps). The goodness-of-fit index is 0.92. This means that the network shown is, at least, a plausible description of causal influences.

The value of the natural environment When councillors were asked which features of the municipality they valued it emerged that they value nature greatly. Unprompted, $81 \%$ of the councillors mentioned they personally value natural features most in their municipality and $100 \%$ were aware of the importance nature has for tourism.

Perceptions about land-use planning Awareness among councillors of the forward-planning processes as well as 


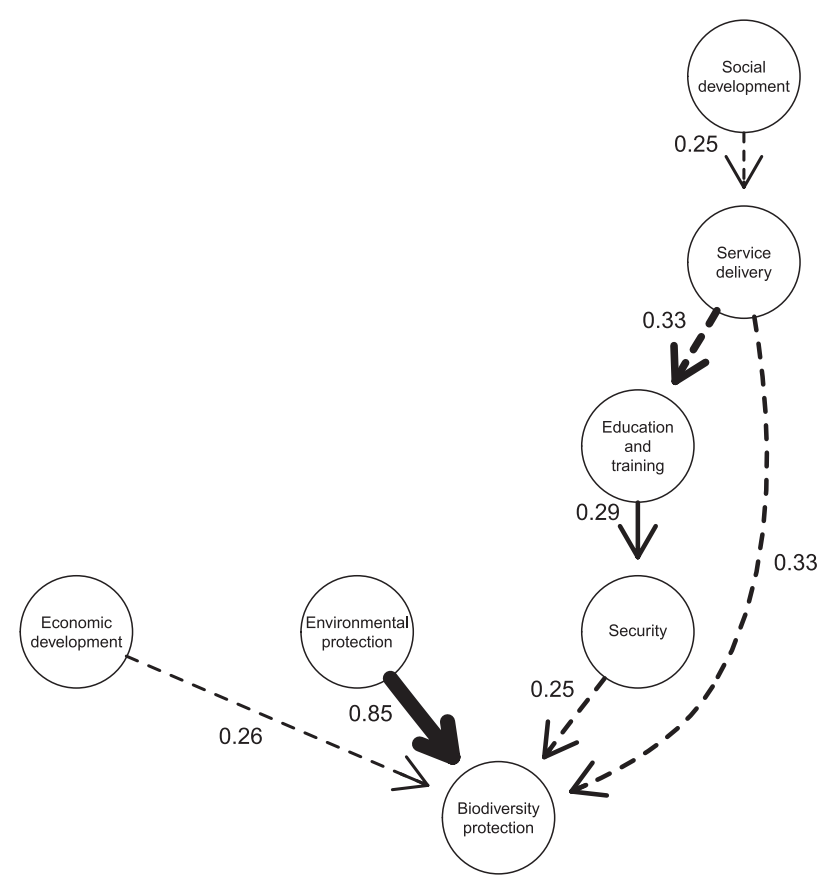

FIG. 3 Path diagram of councillors' priorities. Priorities that influence other priorities are shown using a directed arrow $(\rightarrow)$, with the arrow pointing in the direction of influence. Solid arrows show positive influence, broken arrows show negative influence. Arrow thickness is proportional to the level of confidence. The associated values show the magnitude of the influence if all other influences are held constant.

the land-use administration was high (IDP, $100 \%$; SDF, 73\%; LUP, 95\%), and almost all who were aware valued the planning tools as a positive contribution to the municipality's development (IDP, 95\%; SDF, 93\%; LUP, 100\%). However, there was also a high rate of agreement that these processes are dysfunctional: $81 \%$ (IDP), $70 \%$ (SDF) and $65 \%$ (LUP) of councillors stated that the processes were not working or were at times even counterproductive in their municipalities. Only a few councillors considered the processes as being functional (IDP, $19 \%$; SDF, $3 \%$; LUP, $16 \%)$. For SDF, $27 \%$ of respondents were undecided; for LUP, $19 \%$ were undecided.

Tensions with conservation The role of conservation and its proponents in the respective municipalities was perceived as predominantly negative by $46 \%$ of the councillors. Twentyfour percent perceived them as both negative and positive, $22 \%$ considered them neutral, and $8 \%$ as predominantly positive. One councillor stated: 'The environmentalists are their own biggest enemy'. This result did not vary with party affiliation (Pearson's $\chi^{2}=0.16, \mathrm{P}=0.9840$ ).

Information-seeking behaviour When confronted with a difficult problem, $65 \%$ of councillors chose internal structures of the municipal council as the primary source of information or help, $8 \%$ chose municipal administrative structures, and $11 \%$ internal political party structures. Only $16 \%$ referred to sources outside the municipality. When asked where they would turn in a second step to seek help or information, only $11 \%$ would use printed information or the Internet.

\section{Discussion}

Our results provide insight into the benefits the product (i.e. using the maps) can provide, and conversely what barriers exist to adopting this new behaviour. It needs to be emphasized that we are referring exclusively to benefits and barriers as perceived by the target audience. All other benefits or barriers (e.g. those perceived by other groups such as conservationists) are immaterial for achieving the goal of behaviour change.

Regarding the potential benefits the product could provide we have shown that councillors overwhelmingly value their natural environment personally and are unequivocally aware of the value of nature for tourism. They do perceive an inherent benefit in protecting nature and, by extension, in using the maps, provided this benefit is realized tangibly and not undermined by competing and stronger issues connected with development. We consider this to be the competitive advantage of the maps, which clearly identify areas where development is less destructive to the environment (Pierce et al., 2005), over more traditional approaches aimed at preserving species or ambiguously designated areas. Development and environmental protection are currently perceived by councillors as being mutually exclusive, with development having clear priority (Wilhelm-Rechmann \& Cowling, 2011). As the maps provide a visually compelling scientific assessment of the conservation value of a piece of land, they enable biodiversity considerations to be included in decision-making case by case (Pressey, 1999). The maps, therefore, provide an option to accommodate the development vs biodiversity protection divide by steering developments towards areas least important for biodiversity. Highlighting this aspect will probably help to realize the inherent benefits of safeguarding nature and thus support the goal of behaviour change.

Our results further suggest that the lack of priority accorded to biodiversity and environmental considerations is a core barrier to mainstreaming the maps. The subject of the maps is biodiversity protection, which is neither understood by the majority of the target audience (WilhelmRechmann \& Cowling, 2011) nor has any priority for them. Attempts to change the order of priorities of political issues could be informed by the literature on agenda setting (McCombs, 2005; Andreasen, 2006). The project presented here focuses on mainstreaming the maps only, therefore it makes sense to consider the following option: to link the maps with an issue that is already high on a councillor's 
agenda. Service provision is a key issue at local government level but is currently identified primarily with providing housing, water, electricity and other basic services. Furthermore, we have shown that land-use planning is considered to be an important issue. Biodiversity protection could be linked to service delivery via the concept of ecosystem services (Daily \& Matson, 2008) and their associated spatial features, namely critical natural capital (Chiesura \& De Groot, 2003) or green infrastructure (Naidoo et al., 2008; Termorshuizen \& Opdam, 2009). Ecosystem service maps, especially if they identify natural resources important for the delivery of key services such as water provision and ecotourism, are likely to be much more compelling to the target audience than maps based only on biodiversity features. Clearly, all services mapped need to be described in locally understandable terminology.

The fact that councillors perceive conservationists in predominantly negative terms presents a considerable barrier to the communication process and to the goal of behaviour change. Information provided by conservation professionals is likely to raise little interest and have low credibility (Peters et al., 1997). To confront this challenge, which is likely to be widespread in South Africa and elsewhere, the conservation sector could engage in a rebranding process (Tybout \& Calkins, 2005). In the corporate world re-branding is used when a company wishes to distance itself from negative connotations attached to how it is currently perceived. Quelch \& Laidler-Kylander (2005) provide insight into brand management, including rebranding of a number of not-for-profit organizations, including WWF. They clearly highlight the importance of knowing the value of one's brand and the need to consciously manage public perceptions about an institution. The study presented here, however, focuses on mainstreaming the maps only, therefore we suggest two different strategies, one aimed at establishing the new behaviour, the other at maintaining the behaviour once it has been adopted.

We propose the engagement of the South African Local Government Association, to provide training as a first step to establish the new behaviour. The majority of councillors indicate having received training through the Association, which is therefore an appropriate choice. However, participation in the Association's courses is non-compulsory. Courses on the use of conservation maps are unlikely to attract any interest. Therefore, we suggest offering courses on land-use planning and service provision (including services from nature), as both issues carry a higher priority. Considering that all three planning processes (IDP, SDF and LUP) are considered to be important but dysfunctional, such courses could probably respond to a prevalent training need. Nevertheless, newly established courses specifically on land-use planning will require proactive advertising.
Once the process of adopting the maps has commenced, continued support will be needed to maintain the new behaviour (Andreasen, 1995) and to provide technical expertise on a case-by-case basis when the maps are being used. We therefore suggest establishing long-term relationships (Peters et al., 1997) between conservation agents and the municipalities at both administrative and political level, which could contribute to overcoming the antagonism towards the conservation sector.

With regard to the question of how to reach councillors most effectively (the 'place' component of the ' 4 Ps' marketing approach) our results show that councillors do not usually reach far beyond their municipality for retrieving information. This has dual implications. Firstly, as we have proposed above, messages need to be placed within direct local reach if they are to be retrieved. Using the Internet, for example, to provide information is unlikely to be effective. Secondly, and this pertains to the 'promotion' component of the strategy, the messages themselves need to be meaningful in the local context. Considering the low level of biological literacy, the language and concepts commonly used in conservation planning materials are not conducive to meaningful communication (Jacobson, 1999). Even the term biodiversity is not well understood by councillors (Wilhelm-Rechmann \& Cowling, 2011). Education and training is a major priority of the South African government and was identified by the councillors as the top priority among the seven issues that they were required to rank. We suggest, therefore, that providing councillors with understandable and meaningful information they can use and apply in their daily lives could raise substantial interest. Terminology and applied examples from within each municipality should be used to spur interest and personal engagement and to encourage behaviour change. It is essential that the products provide hands-on, localized knowledge and meaning relevant to the councillors' needs, not just biodiversity information perceived as important by conservationists. Once the interest in the products is established, wider biodiversity concepts may be introduced. We are not proposing to ignore biodiversity issues completely; doing so could lead to a risky subsuming of conservation under the ecosystem services umbrella, possibly limiting conservation to its utilitarian component (Redford \& Adams, 2009). Our results show that councillors' perceptions of nature often include aspects of intrinsic value. However, as biodiversity conservation is negatively perceived by the councillors (Wilhelm-Rechmann \& Cowling, 2011), interest in the products must emerge before complex biodiversity issues are introduced. Lastly, we wish to highlight that there is little interest for politicians in receiving the same specialist training that is suitable for land-use planners or administrators. Instead, councillors need to be empowered with the understanding necessary to fully appraise land development 
issues, including biodiversity protection and the ecosystem services nature provides to their municipalities.

Our data refer to the South African context. However, we surmise that similar conditions may prevail in many highly diverse developing countries, as many share a colonial history. The value of the social marketing approach, and specifically its customer research, lies in unravelling and strategically using the contextual determinants that influence conservation outcomes. Andreasen (1995) points out that social marketing is essentially the mindset of 'putting the customer first', and that achieving this 'customercentered mindset' is challenging. However, it is and has been used successfully in a multiplicity of environments, often with low budgets, and has proven more effective than information and awareness campaigns (Stead et al., 2007).

\section{Acknowledgements}

We gratefully acknowledge all our interviewees for their openness and time.

Funding was provided by National Research Foundation (Pretoria), Nelson Mandela Metropolitan University and the South African National Biodiversity Institute.

\section{References}

Andreasen, A.R. (1995) Marketing Social Change: Changing Behavior to Promote Health, Social Development and the Environment. Jossey-Bass, San Francisco, USA.

Andreasen, A.R. (2006) Social Marketing in the 21st Century. Sage Publications, Thousand Oaks, USA.

Andreasen, A.R. \& Tyson, C.B. (1994) Applying social marketing to ecological problems through consumer research. Asia Pacific Advances in Consumer Research, 1, 22-27.

Beinart, W. (2003) The Rise of Conservation in South Africa: Settlers, Livestock, and the Environment 1770-1950. Oxford University Press, Oxford, UK.

Bollen, K.A. \& Stine, R.A. (1992) Bootstrapping goodness-of-fit measures in structural equation models. Sociological Methods Research, 21, 205-229.

BRAdley, R.A. \& TerRy, M.E. (1952) The rank analysis of incomplete block designs I. The method of paired comparisons. Biometrika, 39, 324-345.

Chiesura, A. \& De Groot, R. (2003) Critical natural capital: a sociocultural perspective. Ecological Economics, 44, 219-231.

Cousins, B., Hoffman, M.T., Allsopp, N. \& Rohde, R.F. (2007) A synthesis of sociological and biological perspectives on sustainable land use in Namaqualand. Journal of Arid Environments, 70, 834-846.

Daily, G.C. \& MATson, P.A. (2008) Ecosystem services: from theory to implementation. Proceedings of the National Academy of Sciences of the USA, 105, 9455-9456.

JACOBSON, S.K. (1999) Communication Skills for Conservation Professionals. Island Press, Washington, DC, USA.

Knight, A.T., Cowling, R.M., Boshoff, A.F., Wilson, S.L. \& Pierce, S.M. (2010) Walking in STEP: lessons for linking spatial prioritisations to implementation strategies. Biological

Conservation, 144, 202-211.

Kotler, P. \& Keller, K.L. (2006) Marketing Management. 12th edition. Pearson Education, New Jersey, USA.

Landers, J., Mitchell, P., Smith, W., Lehman, T. \& Conner, C. (2006) 'Save the crabs, then eat 'em': a culinary approach to saving the Chesapeake Bay. Social Marketing Quarterly, 12, $15-28$.

Maathuis, M., Colombo, D., Kalisch, M. \& Bühlmann, P. (2010) Predicting causal effects in large-scale systems from observational data. Nature Methods, 7, 247-248.

Margules, C.R. \& Pressey, R.L. (2000) Systematic conservation planning. Nature, 405, 37-47.

MсСомвs, M.E. (2005) A look at agenda-setting: past, present and future. Journalism Studies, 6, 543-557.

Miller, J.R., Groom, M., Hess, G.R., Steelman, T., Stokes, D.L., Thompson, J. et al. (2008) Biodiversity conservation in local planning. Conservation Biology, 23, 53-63.

Naidoo, R., Balmford, A., Costanza, R., Fisher, B., Green, R.E., Lehner, B. et al. (2008) Global mapping of ecosystem services and conservation priorities. Proceedings of the National Academy of Sciences of the USA, 105, 9495-9500.

Opdam, P., Foppen, R. \& Vos, C.C. (2002) Bridging the gap between ecology and spatial planning in landscape ecology. Landscape Ecology, 16, 767-779.

Palmer, B.J., McGregor, G.K., Hill, T.R. \& Paterson, A.W. (2010) A spatial assessment of coastal development and land use change in the Eastern Cape, South Africa. South African Geographical Journal, 92, 117-128.

Peters, R.G., Covello, V.T. \& McCallum, D.B. (1997) The determinants of trust and credibility in environmental risk communication: an empirical study. Risk Analysis, 17, 43-54.

Pierce, S.M., Cowling, R.M., Knight, A.T., Lombard, A.T., Rouget, M. \& Wolf, T. (2005) Systematic conservation assessment products for land-use planning: interpretation for implementation. Biological Conservation, 125, 441-458.

Pressey, R.L. (1999) Applications of irreplaceability analysis to planning and management problems. Parks, 9, 42-51.

Quelch, J.A. \& Laidler-Kylander, N. (2005) The New Global Brands: Managing Non-Government Organizations in the 21st Century. Cengage Learning, Andover, UK.

R Development Core Team (2010) R: A Language and Environment for Statistical Computing. Vienna, Austria. Http://www.R-project. org [accessed July 2011].

Redford, K.H. \& Adams, W.M. (2009) Payment for ecosystem services and the challenge of saving nature. Conservation Biology, $23,785-787$.

Reyers, B., Rouget, M., Jonas, Z., Cowling, R.M., Driver, A., Maze, K. \& Desmet, P.G. (2007) Developing products for conservation decision-making: lessons from a spatial biodiversity assessment for South Africa. Diversity and Distributions, 13, 608-619.

Shipley, B. (2000) A new inferential test for path models based on directed acyclic graphs. Structural Equation Modeling, 7, 206-218.

Spirtes, P., Glymour, C. \& Scheines, R. (2000) Causation, Prediction, and Search: Adaptive Computation and Machine Learning. MIT Press, Cambridge, USA.

StatsSA (Statistics South Africa) (2009) Community Survey 2007: Basic Results-Eastern Cape. Report No. 03-01-32. Statistics South Africa, Pretoria, South Africa. Http://www.statssa.gov.za/ publications/statsdownload.asp?PPN=Report-03-01-32\&SCH=4626 [accessed January 2011]. 
Stead, M., Gordon, R., Angus, K. \& McDermott, L. (2007) A systematic review of social marketing effectiveness. Health Education, 107, 126-191.

Steenkamp, J-B., De Jong, E.M., Martijn, G. \& Baumgartner, H. (2010) Socially desirable response tendencies in survey research. Journal of Marketing Research, 47, 199-214.

Stokes, D.L., Hanson, M.F., Oaks, D.D., Straub, J.E. \& Ponio, A.V. (2010) Local land-use planning to conserve biodiversity: planners' perspectives on what works. Conservation Biology, 24, 450-460.

Strobl, C., Wickelmaier, F. \& Zeileis, A. (2009) Accounting for Individual Differences in Bradley-Terry Models by Means of Recursive Partitioning, Technical Report Number 54. Department of Statistics, University of Munich, Munich, Germany. Http://www. stat.uni-muenchen.de/ carolin/dfg_projekt.html [accessed January 2011].

Termorshuizen, J. \& Opdam, P. (2009) Landscape services as a bridge between landscape ecology and sustainable development. Landscape Ecology, 24, 1037-1052.

Theobald, D.M., Hobbs, N.T., Bearly, T., Zack, J., Shenk, T. \& Riebsame, W.E. (2000) Incorporating biological information into local land-use decision making: designing a system for conservation planning. Landscape Ecology, $15,35-45$.

Tyвout, A. \& Calkins, T. (2005) Kellogg On Branding. Wiley, New Jersey, USA.

VAn Wyk, J. (1999) Planning Law: Principles and Procedures of Land-Use Management. Juta, Kenwyn, South Africa.

Whiteman, G. (1999) Sustainability for the planet: a marketing perspective. Ecology and Society, 3(1).
Http://www.ecologyandsociety.org/vol3/iss1/art13 [accessed 19 June 2013].

Wilhelm-Rechmann, A. \& Cowling, R.M. (2008) Social marketing as an implementation tool in complex social-ecological systems. In Exploring Sustainability Science: A Southern African Perspective (eds M. Burns \& A. Weaver), pp. 179-204. SUN Press, Stellenbosch, South Africa.

Wilhelm-Rechmann, A. \& Cowling, R.M. (2011) Framing biodiversity conservation for decision makers: insights from four South African municipalities. Conservation Letters, 4, 73-80.

Wilhelm-Rechmann, A. \& Cowling, R.M. (2013) Local land-use planning and the role of conservation: an example analysing opportunities. South African Journal of Science, 109, 1-6.

ZAFIrovski, M. (2003) Some amendments to social exchange theory: a sociological perspective. Theory \& Science, 4(2). Http:// theoryandscience.icaap.org/content/voloo4.002/01_zafirovski.html [accessed June 2010].

\section{Biographical sketches}

Angelika Wilhelm-Rechmann is interested in the use of psychology and social science concepts to effect human behaviour change for conservation goals. She focuses on analysis of those parts of our societies that are not conservation oriented but hold the power to influence conservation outcomes. RICHARD COWLING is interested in the biophysical and social components of conservation science for effective implementation. He keeps himself sane by researching the origins of plant diversity in the Cape of South Africa. 